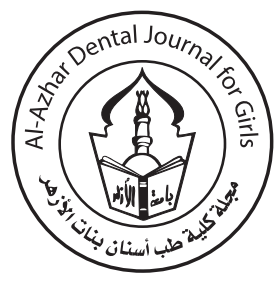

\title{
Oral Health Status of Children Undergoing Hemodialysis and Kidney Transplantation in Mansoura City, Egypt
}

\author{
Nayera T. El-Saied ${ }^{1}$, Salwa M. Awad ${ }^{2}$, Tarek M. Abbas ${ }^{3}, \operatorname{Rasha~I.~Ramadan}^{4 *}$
}

\section{Codex : 19/21.01 \\ azhardentj@azhar.edu.eg \\ http://adjg.journals.ekb.eg \\ DOI: 10.21608/adjg.2021.41603.1290 \\ Pediatric Dentistry \& Orthodontics ( Pediatric Dentistry, Orthodontics)}

\section{KEYWORDS}

Chronic kidney disease, enamel developmental defects, oral health.

\begin{abstract}
Purpose: Evaluation of oral health status in children undergoing hemodialysis sessions and kidney transplantation and compared them with healthy children. Materials and Methods: This descriptive study was conducted on 250 children aged 6-18 years old (100 children undergoing hemodialysis, 50 children undergoing kidney transplantation and 100 healthy children as a control group). The oral health status was evaluated regarding to caries experience, gingivitis using PMA index, developmental defects using modified DDE index. Un-stimulated salivary flow rate and $\mathrm{pH}$ were also measured. Results: caries experience was significantly lower in both chronic kidney disease (CKD) groups compared to control group. Median PMA was significantly higher in hemodialysis and in transplantation groups compared to control group. The prevalence of developmental enamel defects was $41 \%$ in hemodialysis group and $58 \%$ in transplantation group compared to $11 \%$ in control group (P-value $<0.001$ ). Regarding to saliva analysis, the flow rate was higher among healthy children while the salivary PH was higher among children with CKD. Conclusions: chronic kidney disease may decrease caries experience, increase gingival inflammation, in addition to increase prevalence of developmental defects. Furthermore, children with chronic kidney disease have lower salivary flow rate and higher buffering capacity than healthy children.
\end{abstract}

- Paper extracted from Master thesis titled 'Oral Health Status of Children undergoing Hemodialysis and Kidney Transplantation",

1. Dentist at Ministry of Health and Population, Mansoura, Egyp.

2. Professor of Pediatric Dentistry, Department of Pediatric Dentistry and Dental Public Health, Faculty of Dentistry, Mansoura University , Egypt.

3. Professor of Internal Medicine and Nephrology, Urology and Nephrology Center, Faculty of Medicine, Mansoura University, Egypt.

4. Lecturer of Dental Public Health and Preventive Dentistry, Department of Pediatric Dentistry and Dental Public Health. Faculty of dentistry, Mansoura University, Egypt.

* Corresponding author email: elmaghrabyrasha@yahoo.com 


\section{INTRODUCTION}

Oral health can be considered as a predictor of general health. Nearly $90 \%$ of patients suffering from chronic renal failure (CRF) have oral symptoms that affect both hard and soft tissue. These manifestations may be caused by etiologic factors of kidney disease, or the process of dialysis, and kidney transplantation ${ }^{(1-4)}$.The oral manifestations of the children suffering from chronic renal failure are mainly depend on the age of the child at the onset of the disease, the type of kidney disease, specific conditions of the host and the administered medication $^{(5)}$.

Many researches have stated low caries prevalence $(8.5 \%)$ among patients with CKD compared to their control groups (40\%) this may be due to elevated buffering capacity of saliva as a result of high level of salivary urea and a low count of Streptococci mutans. Additionally, an alternation in production of acid in kidney disease patients due to high concentration of salivary urea, which leads to less $\mathrm{H}+$ ion production by dental plaque ${ }^{(6-8)}$.

Gingival inflammation was noticed significantly in children suffering from CKD compared to healthy children. This may be related to the prescribed drugs; it was found that children undergoing treatment with nifedipine and/or cyclosporine A had higher prevalence of gingivitis ${ }^{(6,7,9)}$.

Renal dysfunction can cause enamel hypoplasia. It was observed that children suffering from renal failure had high prevalence of developmental defects of enamel ranged from $57 \%$ to $83 \%$ in permanent teeth ${ }^{(6,10)}$. The position and the extent of the defects are critically depending on the age of the patient, timing and duration of the systemic metabolic disease. Another factor responsible for the disruption of the enamel defects is abnormal calcium-phosphorous metabolism. This causes an elevation in serum $\mathrm{P}$ and a reduction of plasma $\mathrm{Ca}$. Thus, the enamel defects were reported in children suffering from $\mathrm{Ca}$ deficiency ${ }^{(6,11)}$. Moreover, the plasma fluoride concentration may be elevated due to renal dysfunction, leading to dental fluorosis. Dental fluorosis was recorded among $77 \%$ of the populations with chronic kidney disease ${ }^{(5,12)}$.

Alterations in salivary $\mathrm{Ca}, \mathrm{P}$, magnesium and elevated salivary $\mathrm{pH}$ were established in Patients with CRF; furthermore, increased salivary urea lead to precipitation of $\mathrm{Ca}-\mathrm{P}$ and $\mathrm{Ca}-\mathrm{Ox}{ }^{(11)}$.

One of the major oral symptoms among renal failure child is oral malodor. It commonly occurs due to infections, xerostomia, and bad oral hygiene. The major cause of uremic odors which may occur in $71.1 \%$ of CRF patients is the presence of toxins due to inadequate clearance during dialysis ${ }^{(13)}$.

Inter consultation between physician and dentist is essential in pediatric patients with chronic kidney disease. It should be performed as early as possible. The dentist can educate the mother about hygiene care of the child, risk factors for dental caries and use of preventive measures to minimize the risk of oral diseases ${ }^{(6)}$.

Depending on the clinical situation of the child; a preventive program must be planned and mandatory followed each 3 months ${ }^{(14,15)}$. Dental treatment in patients undergoing hemodialysis is suitable to be performed the day after renal dialysis as there is an electrolyte balance. While surgical intervention is advised not to be performed before eight hours after renal dialysis ${ }^{(15,16)}$.

It was found that Patients suffering from kidney disease have an elevated level of fluoride in plasma, so systemic fluoride is contraindicated. Furthermore, the dentist should advices the use of alcohol-free mouth wash and artificial saliva in CRF patients to minimize the risk of xerostomia ${ }^{(15)}$.

It is critical to remove any source of infection in the mouth as soon as possible especially in patients who has problems in the heart in addition to renal dysfunction. Antibiotic prophylaxis should be prescribed if there is risk of septicemia in case of placement of orthodontic appliances, periodontal treatment, extractions, endodontic treatment and periapical surgery,...etc. ${ }^{(14,17)}$. 
Although the presence of such researches in this field in the world wide but there is a limited data in Egypt about oral and dental changes in children suffering from chronic renal failure who undergoing dialysis or transplantation therapy. Therefore, this study was conducted to assess the oral health status among these patients.

\section{MATERIALS AND METHODS}

A descriptive cross sectional study design was used. All children of both gender with an age ranged from 6-18 years; undergoing hemodialysis and kidney transplantation from October 2018 to October 2019 were included. The total number of them was 150 children (100 children were undergoing hemodialysis and 50 children were undergoing kidney transplantation). Children maintain regular hemodialysis was selected from Pediatric Nephrology clinic, Pediatric Hospital at Mansoura University; while children with kidney transplantation were selected from Mansoura Urology and Nephrology Center. A number of 100 Children with the same age range, gender and socioeconomic status to the study group and who were free from any systemic disease were included as a control group. They were selected from governmental schools, Mansoura city.

This study was performed after an approval from Ethical committee of the Faculty of Dentistry, Mansoura University. An informed written consent was taken from the parent of each child after a brief description of the study protocol.

The clinical examination of all cases was performed by one examiner. To ensure consistency of examination a group of 20 healthy children were examined by the same examiner using all indices used in this study. By comparing the results of the two examinations the agreement Kappa value ${ }^{(18)}$ was $(95 \%)$.

The clinical examination was done visually for each child under a good source of artificial light, using mouth mirror and a dental probe. The diagnosis was done According to the criteria published by the
World Health Organization (WHO) ${ }^{(19)}$ using dft index for deciduous teeth and DMFT index for permanent teeth ${ }^{(20,21)}$.The tooth was considered decayed if there is undermining of enamel, cavitation, softening in base or wall, temporary filling, recurrent caries and remaining root.

Each child was evaluated for any gingival inflammation using Papillary, Marginal and Attached (PMA) Index ${ }^{(22)}$; Score 0: Normal, no inflammation. Score 1: presence of inflammation. PMA Index per person is the sum of all the scores.

The Modified Developmental Defects of Enamel Index (Modified

DDE Index $)^{(23)}$ was used to diagnose any changes in the enamel. The labial or buccal surface of 8 index permanent teeth was examined (bilateral $1^{\text {st }}$ and $2^{\text {nd }}$ maxillary incisors, bilateral maxillary first premolars, and bilateral first mandibular molars)

Score 1 for Demarcated opacity, score 2 for diffuse opacity, score 3 for Hypoplasia pits and score 4 for other defects. For the Modified DDE Index ${ }^{(23)}$, the results were expressed as frequency or percentage distribution not mean scores.

For saliva sample; The child instructed not to eat or drink, not chewing any chewing gums, not brush their teeth and not use any mouthwashes for one hour prior to saliva collection (un-stimulated saliva). Child was allowed sitting upright position on the chair and relaxing for a few minutes then saliva allowed to droll into a graduated container with funnel continuously for 5 minutes without making any mechanical movements of the mouth ${ }^{(24)}$. The collection of saliva was done between 9 and $12 \mathrm{am}$.

The saliva flow rate was determined by the amount of saliva collected at graduated tubes for 5 minutes, the results were converted to $\mathrm{ml}$ per minute. Unstimulated salivary flow rate in normal person is $0.3-0.4 \mathrm{ml}$ per minute and below $0.1 \mathrm{ml}$ per minute is significantly abnormal ${ }^{(24)}$. 
Salivary $\mathrm{pH}$ value was measured by using Universal Test Paper (DF) with complete four color indicator chart by placing $0.5 \mathrm{ml}$ of each saliva sample using plastic syringe on absorbent surface of PH strip with the pad facing up. The color change was assessed after 30 seconds. The result was obtained by comparing the color which has developed with that on the color chart ${ }^{(24)}$

The data were statistical analyzed using the Statistical Package of Social Science SPSS version 21(SPSS, Inc., Chicago, IL, USA). The data were examined for normal distribution using Kolmogorov-Smirnov test. Qualitative data were presented as number and percentage and compared using chi-square test. Quantitative data were presented as mean and standard deviation for parametric data and median (min-max) for non-parametric data. Mann-Whitney test was used to compare means of two groups. One-Way ANOVA test (for parametric data) and Kruskal- Wallis test (for nonparametric data) were used to compare means of more two groups. A P-value of $\leq 0.05$ was considered to be statistically significant.

\section{RESULTS}

It was found that the caries prevalence was significantly lower in kidney disease groups than control group. It was 55\% and 54\% in kidney disease groups compared to $77 \%$ in control group (P value $\leq 0.05)$. (Table 1)
Concerning to gingival condition among the studied group; it was revealed that the median PMA scores significantly increased with age among all groups; in addition to that the gingivitis was significantly higher among the transplantation group and hemodialysis group than the control group ( $\mathrm{P}$ value $\leq 0.05$ ). (Table 2 )

Regarding to Developmental defects, it was found that kidney disease groups have higher prevalence of developmental defects than the control group. The transplantation group have the highest prevalence of developmental defects (58\%) followed by hemodialysis group (42\%) while in control group it was (11\%) and this difference was statistically significant $(\mathrm{P}$ value $\leq 0.05)$ and the highest defect in all studied groups was demarcated opacity (score 1). (Table 3)

For salivary test, it was found that salivary flow rate was higher in control group $(0.281 \pm 0.15)$ followed by hemodialysis group $(0.231 \pm 0.12)$ and then transplantation group $(0.215 \pm 0.09)$. But these differences were only significant between transplantation and control groups. In the other hand the salivary $\mathrm{PH}$ was higher among children with chronic kidney disease than healthy children, and these difference was statistically significant $(\mathrm{P}$ value $\leq 0.05)($ table 4$)$

Table (1): Dental caries prevalence and experience among the studied groups:

\begin{tabular}{|c|c|c|c|c|c|c|}
\hline Groups & $\begin{array}{c}\text { Caries prevalence } \\
\text { n }(\%)\end{array}$ & $\begin{array}{c}P \text { value of } \\
x^{2} \text { test }\end{array}$ & $\begin{array}{l}\text { DMFT } \\
\mathrm{X}^{-} \pm \mathrm{SD}\end{array}$ & $\begin{array}{c}\text { P value of } \\
\text { ANOVA Test }\end{array}$ & $\underset{X \pm \text { dft }}{\mathbf{X} D}$ & $\begin{array}{c}\text { P value of } \\
\text { ANOVA Test }\end{array}$ \\
\hline $\begin{array}{c}\text { Hemodialysis } \\
\quad \mathrm{N}=100\end{array}$ & $55(55 \%) \mathrm{a}$ & \multirow{3}{*}{$0.002 *$} & $1.25 \pm 1.8$ & \multirow{3}{*}{0.810} & $0.39 \pm 1.2 \mathrm{a}$ & \multirow{3}{*}{$<0.001 *$} \\
\hline $\begin{array}{c}\text { transplantation } \\
\mathbf{N}=\mathbf{5 0}\end{array}$ & $(54 \%)$ b 27 & & $1.34 \pm 1.8$ & & $0.46 \pm 1.1 \mathrm{~b}$ & \\
\hline $\begin{array}{c}\text { Control } \\
\mathrm{N}=100\end{array}$ & $77 \quad(77 \%) \mathrm{ab}$ & & $1.42 \pm 1.9$ & & $1.68 \pm 2.6 \mathrm{ab}$ & \\
\hline
\end{tabular}

$N$ : number of children within each group.

$n$ : number of children affected by caries in each group.

$a, b$ : similar letters include significant differences between groups $P \leq 0.05$

* : significant difference $P \leq 0.05$. 
Table (2): Gingival condition using PMA index in relation to age:

\begin{tabular}{|c|c|c|c|}
\hline Groups & $\begin{array}{c}\text { PMA median (Max-Max) } \\
\text { 6-12years } \\
\text { >12 years }\end{array}$ & $\begin{array}{c}\text { p value } \\
\text { of Mann } \\
\text { whitney test }\end{array}$ \\
\hline Hemodialysis & $\begin{array}{c}12.00 \\
(0.0-52) \mathrm{ab}\end{array}$ & $\begin{array}{c}26.00 \\
(0.0-65) \mathrm{a}\end{array}$ & $<0.001^{*}$ \\
\hline Transplantation & $\begin{array}{c}19.00 \\
(0.0-56) \mathrm{ac}\end{array}$ & $\begin{array}{c}31.00 \\
(4.00-56) \mathrm{ab}\end{array}$ & $0.008^{*}$ \\
\hline Control group & $\begin{array}{c}8.00 \\
(0.0-40) \mathrm{bc}\end{array}$ & $\begin{array}{c}24.00 \\
(0.0-42) \mathrm{b}\end{array}$ & $<0.001^{*}$ \\
\hline $\begin{array}{c}\text { P value of } \\
\text { Kruskal wallis } \\
\text { test }\end{array}$ & $0.009 *$ & $0.002^{*}$ & \\
\hline
\end{tabular}

Mann Whitney test was used to compare between two medians

Kruskal Wallis test was used to compare between more than two medians

$a, b, c:$ similar letters include significant difference between groups

Table (3): The prevalence of different scores of developmental defects among studied groups:

\begin{tabular}{|c|c|c|c|c|}
\hline Groups & $\begin{array}{c}\text { Hemodialysis } \\
\mathbf{N = 1 0 0}\end{array}$ & $\begin{array}{c}\text { Transplantation } \\
\mathbf{N}=\mathbf{5 0}\end{array}$ & $\begin{array}{c}\text { Control } \\
\mathbf{N = 1 0 0}\end{array}$ & $\begin{array}{c}\text { P value } \\
\text { of } \\
\mathbf{X}^{2} \text { test }\end{array}$ \\
\hline \multicolumn{5}{|c|}{ Total prevalence of developmental defects } \\
\hline $\begin{array}{c}\text { Affected } \\
\text { n (\%) }\end{array}$ & $42(42 \%) \mathrm{ab}$ & $29(58 \%) \mathrm{ac}$ & $11(11 \% \mathrm{bc}$ & $<0.001 *$ \\
\hline \multicolumn{5}{|c|}{ Different scores of Modified DDE Index } \\
\hline $\begin{array}{c}\text { Score 1 } \\
\mathbf{n}(\%)\end{array}$ & $20(20 \%) \mathrm{a}$ & $17(34 \%) \mathrm{b}$ & $10(10 \%) \mathrm{ab}$ & $0.002 *$ \\
\hline $\begin{array}{c}\text { Score 2 } \\
\mathbf{n}(\%)\end{array}$ & $9(9 \%) \mathrm{ab}$ & $11(22 \%) \mathrm{ac}$ & $2(2 \%) \mathrm{bc}$ & $<0.001 *$ \\
\hline $\begin{array}{c}\text { Score 3 } \\
\mathbf{n}(\%)\end{array}$ & $18(18 \%) \mathrm{a}$ & $13(26 \%) \mathrm{b}$ & $3(3 \%) \mathrm{ab}$ & $<0.001 *$ \\
\hline $\begin{array}{c}\text { Score 4 } \\
\mathbf{n}(\%)\end{array}$ & $10(10 \%) \mathrm{a}$ & $2(4 \%) \mathrm{b}$ & $0(0 \%) \mathrm{a}$ & $0.004 *$ \\
\hline
\end{tabular}

$N$ : number of children within each group.

$n$ : number of children affected by developmental defects in each group.

$a, b, c$ : dissimilar letters include significant difference between groups

*: significant difference $P$-value $\leq 0.05$

Score 1:Demarcated opacity, score 2:diffuse opacity, score 3: Hypoplasia and score 4: other defects
Table (4): Salivary flow rate and $\mathrm{pH}$ among the studied groups:

\begin{tabular}{|c|c|c|}
\hline Groups & $\begin{array}{c}\text { Flow rate } \\
\left(\mathbf{X}^{-} \pm \text {SD) }\right.\end{array}$ & $\begin{array}{c}\mathbf{p H} \\
\left(\mathbf{X}^{-} \pm \mathbf{S D}\right)\end{array}$ \\
\hline $\begin{array}{c}\text { Hemodialysis } \\
(\mathbf{N}=\mathbf{1 0 0})\end{array}$ & $0.231 \pm 0.12 \mathrm{a}$ & $7.54 \pm 0.70 \mathrm{ab}$ \\
\hline $\begin{array}{c}\text { Transplantation } \\
(\mathbf{N}=\mathbf{5 0})\end{array}$ & $0.215 \pm 0.09 \mathrm{~b}$ & $6.98 \pm 0.82 \mathrm{ac}$ \\
\hline $\begin{array}{c}\text { Control } \\
(\mathbf{N}=\mathbf{1 0 0})\end{array}$ & $0.281 \pm 0.15 \mathrm{~b}$ & $6.45 \pm 0.82 \mathrm{bc}$ \\
\hline $\begin{array}{c}\text { P value of } \\
\text { ANOVA Test }\end{array}$ & $0.029 *$ & $<0.001 *$ \\
\hline
\end{tabular}

$a, b, c$ : dissimilar letters include significant difference between groups

*: significant difference $P$-value $\leq 0.05$

\section{DISCUSSION}

This study was conducted on children with CKD who undergoing hemodialysis and kidney transplantation therapies to evaluate their oral health status that considers as an important component of general health and affects positively on individual's quality of life ${ }^{(25)}$.

Dental caries was detected using dft and DMFT indices which are considered the simplest and the most commonly used index in epidemiological surveys of dental caries. This caries index assesses dental health status depending on the number of carious, missing, and filled teeth. Due to its simplicity and accuracy as it provides an indicator of both current and past caries experience is considered the most popular population-based measure of caries experience all over the world ${ }^{(26)}$.

The PMA index was used to evaluate the gingival condition. The reason for its selection was its simplicity to be faster and less invasive with exhausted children under hemodialysis in addition to reduce the risk of infection ${ }^{(22)}$.

The Modified Developmental Defects of Enamel Index was used to allow measuring enamel defects and their severity. It used for general screening 
purpose which recommended that only three basic types of defects be recorded; demarcated opacity, diffuse opacity and hypoplasia. If any other defect does not fall into these categories, it is scored as other defects ${ }^{(27)}$.

The un-stimulated saliva was collected instead of the stimulated saliva because most researches have reported that it is a good determinant of oral dryness as it reflects the function of gland ${ }^{(29,30)}$.

It was found that children with chronic kidney diseases had lower caries prevalence than healthy child which may be attributed to protective effect of high level of salivary urea, which prevents bacterial activity and facilitate the neutralization of acids within bacterial plaque and may also enhance the remineralization process of early carious lesions. That is in agreement with several studies all over the world as the caries prevalence in kidney diseased patient among these studies ranged from $26 \%$ to $55 \%{ }^{(8,14,26,30-33)}$.

On the other hand, Wibbon et al ${ }^{(34)}$ and Brock et al ${ }^{(35)}$ reported high caries prevalence among CRF children. They explained that high caries prevalence by high consumption of cariogenic sugary diet as snacks, ice cream, sweet milk and candy.

At the present study, marked gingivitis was determined in children undergoing hemodialysis and kidney transplantation compared with the control group. This can be explained by neglecting oral hygiene measures, the underlying uremic stomatitis and the use of recombinant erythropoietin which may reduce gingival paleness. That is in agreement with Brock et al. ${ }^{(35)}$, Abdellatif et al. ${ }^{(36)}$ and Gaetano et al. ${ }^{(32)}$ who reported significantly higher gingivitis in children undergoing hemodialysis compared with the controls.

It was found that CRF patients have high prevalence of enamel defects especially for patients who undergoing kidney transplantation (58\%).This result can be explained by occurring of disruption during histo-differentiation, apposition and miner- alization stages during tooth development results in structure abnormalities and abnormal calcium and phosphate metabolism. That was confirmed by others who reported developmental enamel defects in CRF patients ranged from (46.4\% to $83 \%$ ) among their studies ${ }^{(6,10,36,37)}$.

Furthermore, the intrinsic stains resulted from adsorption of pathological pigments onto the dentine matrix especially when uremia is present during dentitions development. The severity of intrinsic stain is mainly related to age of patient at presentation time of renal dysfunction, the duration of renal failure and dialysis ${ }^{(37)}$.

It was found that the most prominent form of developmental defect was demarcated opacities. As renal dysfunction results in calcium deficiency; which often leads to tooth structure abnormalities (like opacities and hypoplasia) ${ }^{(37)}$.

In spite of that, wiboon et al. ${ }^{(34)}$ reported low prevalence of developmental enamel defects which occurred in $27.8 \%$ of CRF patients. This finding was explained by the early management of the renal diseases prior to renal transplantation, which may reduce any metabolic disturbance and subsequently minimize any calcification abnormalities or dental developmental defects.

Regarding to salivary flow rate, it was found that there was no significant difference in un-stimulated salivary flow rate between children undergoing hemodialysis and control group .That's may be due to hemodialysis process has a transient stimulatory effect on the salivary flow rate resulting in higher salivary flow after completion of hemodialysis sessions than before the start of sessions. That was confirmed by several studies. The researchers among these studies did not observe any decrease in salivary flow rate in post dialysis patients when compared to healthy subjects because once the hemodialysis process is terminated; the water balance are within normal levels ${ }^{(1,6,68-40)}$. 
For children undergoing kidney transplant therapy, the salivary flow rate was lower than control group. That may be due to the side effects of medications they received as antihypertensive drugs, corticosteroids that cause lowering in salivary flow rate. That was confirmed by Anuradha et al ${ }^{(40)}$ and kumar et al. ${ }^{(41)}$ who reported reduced salivary flow rate in children and adolescents undergoing long term use of a long acting B2-agonist and a corticosteroid.

Concerning to salivary $\mathrm{pH}$, higher un-stimulated salivary $\mathrm{pH}$ was reported in children with CRF than control group. This result was attributed to higher ammonia concentration in saliva that results from the decomposition of the salivary urea into ammonium ions and carbon dioxide by urease enzyme that may elevate salivary $\mathrm{pH}^{(6,27,36,42)}$.

\section{CONCLUSION}

Chronic kidney disease has many adverse effects on oral health status among children. CKD may increase gingival inflammation, in addition to increase prevalence of developmental defects. In spite of that it may decrease caries experience. Furthermore, children with chronic kidney disease have lower salivary flow rate and higher buffering capacity than healthy children.

\section{REFERENCES}

1. Dioguardi M, Caloro G, Troiano G, Giannatempo G, Laino L, Petruzzi M, Lo Muzio L.. Oral manifestations in chronic uremia patients. Ren Fail. 2015: 1-6.

2. Oyetola E, Owotade F, Agbelusi G, Fatusi O, Sanusi A. Oral findings in chronic kidney disease: implications for management in developing countries. BMC Oral Health. 2015: 15-24.

3. Deschamps S, Martin R, Hannedouche T, Huck O. Association between periodontitis and chronic kidney disease: systematic review and meta-analysis. Oral Dis. 2019;25:385-402.

4. Pereira O, Simões L, Araujo R, Sousa J, Braga A, Soares I, et al. Influence of dialysis therapies on oral health: a pilot study. Quintessence Int. 2019;50:216-23.
5. Schmalz G, Patschan, S, Patschan, D.Oral health-related quality of life in adult patients with end-stage kidney diseases undergoing renal replacement therapy - a systematic review. BMC Nephrol 2020; 21:154.

6. Cláudia M, Antônio P, Cecília R , Cláudia Ch , Rosane $\mathrm{G}$, Érika T. Is there association between chronic kidney disease and dental caries? A case-controlled study. Med Oral Patol Oral Cir Bucal. 2019; 24:211-6.

7. Yue Q, Yin F, Zhang Q, Yuan C, Ye M-Y, Wang X-L, et al. Carious status and supra gingival plaque microbiota in hemodialysis patients. PLoS ONE 2018; 13: e0204674.

8. Andaloro C, Sessa C, Bua N, Mantia I. Chronic kidney disease in children: Assessment of oral health status. Dent Med Probl. 2018; 55:23-8.

9. McDonald R, Avery D, Stookey G, Chin J, Kowolik J. Dentistry for the child and adolescent. 10th ed. Missouri: Mosby Elsevier. 2015:366-400.

10. Maryam Q, Wafaa A. Oral Health Status of Children undergoing Renal Dialysis in Alexandria, Egypt. ADJ.2019;44: 32-7

11. Rodrigues R, Andrade W, Siqueira W, Blumenberg C, Macedo L, Cardoso S, Flores C, Paranhos L. Saliva as an alternative to blood in the determination of uremic state in adult patients with chronic kidney disease: a systematic review and metaanalysis. Clin Oral Investig. 2020;24:2203-17.

12. Rivas UO, Loza R, Sacsaquispe SJ , Calderón V. Clinical and Radiographic Oral Manifestations in Pediatric Patients with Chronic Renal Failure on Dialysis Therapy. Austin J Nephrol Hypertens. 2018; 5: 1077.

13. Taner A, Gülnihal D, Mustafa K, Alper K . Comparison of Systemic Oral Malodor in Patients Undergoing Hemodialysis and Peritoneal Dialysis. Eur J Gen Med 2014; 11:256-61.

14. Dencheva M., Deliverska E, Krasteva E, Galabov J, Kisselova A. Aspects of Renal Disease Affecting Dental Management - Surgery in Patients Receiving Hemodyalisis, Updates in Hemodialysis, Hiromichi Suzuki, IntechOpen.2015.

15. Durgaraju M, Lingam A ,Swapna P, Koppolu C, Bathini. Guide lines for the management of chronic kidney disease Patients in dental setup.J Res Adv Dent 2014;3:62-8.

16. Gupta M, Gupta M, Abhishek. Oral conditions in renal disorders and treatment considerations - A review for pediatric dentist. Saudi Dent J. 2015;27:113-9.

17. Kaswan S,Patil S, Maheshwari S, Wadhawan R.Prevalence of oral lesions in kidney transplant patients: A single center experience. Saudi J Kidney Dis Transpl 2015;26:678-83. 
18. Vanbelle S. Comparing dependent kappa coefficients obtained on multilevel data. Biom J 2017;59:1016-34.

19. World Health Organization, Oral Health Surveys, basic method, 5thed. Geneva (WHO).2013.

20. Venkatesh B, Sinjana J. Assessment of Oral Health Status in Children Suffering from Nephrotic Syndrome. Int J Sci Stud. 2014; 2:19-23.

21. Hiremath SS. Indices. In: Hire math SS. Textbook of preventive and community Dentistry. $2^{\text {nd }}$ ed. India: Elsevier; 2011:198-221.

22. Soben P. Essential of Preventive and Community Dentistry, 3rd ed.: Arya (Medi). 2008, 147-8.

23. Fabrizio G, Marta M, Denise C, Debora P, Gianna M, Livia O. Elevation of the Esthetic Properties of Developmental Defects of Enamel: A spectrophotometric Clinical Study. Scient Worl J 2015;2015:1-9

24. Andrea F, Lara G,Marcela Z, Tatiana L, Adriana O, Marcelo B. Analysis of Salivary Flow Rate, pH Buffering Capacity, and Creatinine in Individuals undergoing Hemodialysis. Brazilian Research in Pediatric Dentistry and Integrated Clinic 2016; 16:141-7.

25. Spanemberg J, Cardoso J, Slob E, López J. Quality of life related to oral health and its impact in adults. Journal of Stomatology, Oral and Maxillofacial Surgery 2019; 120: 234-9

26. Majda E, Saied E, Rogaia A , Rasmia H. Estimate of DMFT index using teeth most affected by dental caries in Benghazi, Libya. IJADS 2020; 6: 159-62

27. Marcia R, Leandro F, Antonio F, Anna Th . Role of saliva in the caries experience and calculus formation of young patients undergoing hemodialysis. Clin Oral Invest. 2015; 19:1973-80

28. Rukmini J, Sachan R, Sibi N, Meghana A, Malar C. Effect of menopause on saliva and dental health. J Int Soc Prev Community Dent 2018;8:529-33.

29. Sruthi K,Yashoda R, Puranik M. Association between Oral Health Status and Salivary Flow Rate among Individuals with and without Burning Mouth: A case control study. J Indian Assoc Public Health Dent 2020;18:47-53.

30. Dodds M, Roland S, Edgar,M. Saliva A review of its role in maintaining oral health and preventing dental disease. BDJ team 2, 2015;15123

31. Andrade R, Antunes A, Soares M, Leão T, Maia C, Primo G. Lower dental caries prevalence associated to chronic kidney disease: a systematic review. Pediatr Nephrol. 2014; 29:771-8.

32. Gaetano C, Erica V, Costanza F, Mary L, Lorenzo B, Federico B, Vanessa N. Dental Care for Patients with End-Stage Renal Disease and Undergoing Hemodialysis International Journal of Dentistry 2018;1-8.

33. Claudio A, Concetto S, Nicolo B. Chronic kidney disease in children: Assessment of oral health status. Dent Med Probl. 2018; 55: 23-8.

34. Wiboon W, Wilawan W. Oral health status in pediatric patients with renal disease at Srinagarind Hospital, Khon Kaen University, Thiland. J Med Assoc Thai. 2015; 98: 185-91.

35. Brock G, Butterworth C, Matthews J. Local and systemic total antioxidant capacity in periodontitis and health. J Clin Periodontol. 2004; 31:515-21.

36. Abdellatif A, Hegazy S, Youssef J . The oral health status and salivary parameters of Egyptian children on haemodialysis. J Adv Res.2011:1-6.

37. Francisco L, Monica X, Allyson M, Tuelita G,Claudia M, Lucas A. Dental Caries and Developmental Defects of Enamel in Individuals with Chronic Kidney Disease: Systematic review and meta -analysis. Oral Diseases. 2019;25:1446-64.

38. Khanum N, Mysore M, Basappa S, Patil A, Kanwar S. Evaluation of changes in salivary composition in renal failure patients before and after hemodialysis. J Clin Exp Dent. 2017; 9:1340-5.

39. Li-Yu Y, Hsing Ch, Yi-Ching Su, Chi-Chun Ch. The effect of transcutaneous electrical nerve stimulation on increasing salivary flow rate in hemodialysis patients. Oral Diseases 2019;25:133-41

40. Anuradha R, Katta S, Kode S. Oral and salivary changes in patients with chronic kidney disease: A clinical and biochemical study. J Indian Soc Periodontol 2015;19:297-301.

41. Kumar T, Kishore J, Kumari M, Rai A, Rai S, Jha A. Evaluation of salivary Flow Rate, $\mathrm{pH}$, and Buffer Capacities in End-Stage Renal Disease Patients versus A control-a Prospective Comparative Study. J Family Med Prim Care 2020;9:2985-9

42. Rahime R. Can salivary creatinine and urea levels be used to diagnose chronic kidney disease in children as accurately as serum creatinine and urea levels? A case-control study, Renal Failure 2017; 39: 452-7 